\title{
Preceding Crops Selection, Colza Seeding Norms and Dates Optimization in North Kazakhstan
}

\author{
Gulzhanar Shaihina1, Abilzhan Husainov², Guldana Seitova ${ }^{3}$, Gaziza Kaseinova", \\ Aida Mausumbayeva ${ }^{5}$ \\ ${ }^{1}$ “Kokshe” Academy, Kokshetau City, The Republic of Kazakhstan \\ ${ }^{2}$ Environment and Stable Development Research Institute, "Kokshe" Academy, Kokshetau City, \\ The Republic of Kazakhstan \\ ${ }^{3}$ Agricultural Chemistry and Soil Sciences at Technical Disciplines Department, "Kokshe" Academy, \\ Kokshetau City, The Republic of Kazakhstan \\ ${ }^{4}$ Technology and Equipment at Technical Disciplines Department, Zhansugurov State University, \\ Taldykurgan City, The Republic of Kazakhstan \\ ${ }^{5}$ Natural Science Disciplines, Zhansugurov State University, Taldykurgan City, The Republic of Kazakhstan \\ Email: gula.13@mail.ru
}

Received 30 September 2014; revised 24 October 2014; accepted 10 November 2014

Copyright (C) 2014 by authors and Scientific Research Publishing Inc.

This work is licensed under the Creative Commons Attribution International License (CC BY). http://creativecommons.org/licenses/by/4.0/

(c) (i) Open Access

\section{Abstract}

Colza is a relatively new crop for North Kazakhstan. The increase of colza seeds production is restricted by its cultivation technology imperfection. Empiric model of colza for seeds cultivation is designed, allowing using its maximum potential. It was found out that correct preceding crops selection, optimization of norms and dates of colza seeding provide seeds heavy weight crops, reducing crops production cost and increasing cost efficiency at $62 \%$ average.

\section{Keywords}

Colza, Seeding Dates, Seeding Norms, Preceding Crops, Economic Efficiency

\section{Introduction}

Colza plays an important economic role for North Kazakhstan as oil-bearing and feeding crop. Possessing a complex of such valuable characteristics as wide ecological adaptability, cold tolerance, early ripeness, high feeding and seeding productivity that makes it different from many other agricultural crops. That is why it 
should take a worthy place in the structure of cultivation areas. Colza crops in steppe farming agriculture could be used for soil protection from water and wind erosion, for green manure management, struggle with weed vegetation. It is a good preceding crop for most agricultural crops in crop rotation system.

Colza plays an important sanitary role in farming agriculture. Colza role as a renewable energy source is growing everywhere nowadays. Kazakhstan can become one of the biggest suppliers of raw materials to EU countries with the aim of bio fuel processing of colza oil.

Due to its unique biological ductility and resistance to low temperatures colza can be successfully cultivated in most regions with moderate climate including North Kazakhstan [1].

It is necessary to point out that oil crops were not cultivated in the region of North Kazakhstan. Cereal and feeding crops have been cultivated here since the 90s of the twentieth century, grain steam and grain hoed crop rotations were introduced and assimilated [2]. Not typical for this region crops (colza) appeared in the mid 80s of the twentieth century, but it was used as a feeding crop for green food [3]. And only in the beginning of the 21st century, owing to diversification of crops manufacture of North Kazakhstan, colza cultivation for seeds was started [4].

However, colza processing for seeds in North Kazakhstan conditions is restricted by its cultivating technology imperfection. To solve this problem we have studied preceding crops influence in crops rotation system, dates and norms of colza seeding for colza seeds crops producing power. The fact of little research in this area stipulates the relevance of the topic.

Productive potential of Maibulak sort colza was determined for the first time for the conditions of North Kazakhstan depending on seeding dates and norms and preceding crop in crops rotation system. Optimal combination of colza cultivation was determines, the use of which allows to increase crop productivity up to 0.8 - 1.0 tons/ha and provide the level of cost efficiency at $62 \%$ average.

\section{Conditions and Methods of Research}

The climate of North Kazakhstan is heavy continental, winter is cold and there is little snow, summer is hot and droughty. Annual precipitation is only 250 - $300 \mathrm{~mm}$, the sum of active temperatures (higher than 10 degrees) is 2300 - 2400 degrees. Meteorological condition during the years of research were various enough on heat and humidity provision that allowed to characterize the technological ways understudy of colza seeds cultivation completely enough. However, on the whole they were typical of the region.

Colza refers to cabbage class (Cruciferae or Brassicaceae). It is an amphidiploidhybrid of Cole seed (B. camheastris) and cabbage (B. oleraceae). Colza is one of the most cold-season crop. Its seeds begin to grow at soil temperature of $1^{\circ} \mathrm{C}-5^{\circ} \mathrm{C}$, crops can stand frost up to $-3^{\circ} \mathrm{C} \ldots 5^{\circ} \mathrm{C}$, adult plants can vegetate at $2^{\circ} \mathrm{C}-3^{\circ} \mathrm{C}$ and stand autumn frost up to $-8^{\circ} \mathrm{C}$. When seeding at $2-3 \mathrm{~cm}$ crops appear for the 4 th -12 th day depending on soil temperature.

Like many other cabbage class representatives colza is a plant of a long day, sun plant and does not stand shade. In the conditions of artificial shading colza has a longer vegetation period and in heavy seeding decreases its productivity. Getting into the lower layer of cultivated and weed vegetation it is exhausted and thinned out at dirty areas or in mixed seeding. Thus it should be provided with special conditions in mixed seeding for colza to be in the upper seeding and use the energy better [5].

Colza is a wet crop. Its transpiration coefficient is 500 - 750. It is much higher than grain crops. However, according to the efficiency of water consumption colza comes short of wheat 1.5 times. Great water consumption during vegetation period can be stipulated by its need of formation of a bigger than wheat mass. Maximum harvest of green mass is formed in the phase of mass bloom.

Colza can grow on any kind of soil, but it does not stand sour (pH less than 5.8) and watery (with close ground water deposit) soil and also does not grow well on heavy clayish and sandy soil. Fertile average on granulometric compositions soils is more suitable for colza cultivation. In comparison with winter crops colza is less demanding to soil fertility and moisture [6].

The research was conducted during the period of May 2004 to September 2006. To solve the problems under study the following field tests were used:

Test 1. Seeding date influence for colza crops productivity. Test variants: 1) May, 5th; 2) May, 10th; 3) May, 15th; 4) May, 20th; 5) May, 25th—control; 6) May, 30th.

Test 2. Seeding norm influence on colza seeds crops productivity. Test variants: 1) 0.5 million; 2) 1 million; 3) 
2 million; 4) 3 million; 5) 4 million.

Test 3. Preceding crops influence on colza seeds crops productivity. Test variants: 1) subsurface cultivator fallow (control); 2) spreading fallow; 3) combined fallow; 4) occupied fallow (peas + oats); 5) corn; 6) wheat; 7) barley.

Tests repetition is four times. The area of soil lots is $144 \mathrm{~m}^{2}$, accounting area is $50 \mathrm{~m}^{2}$. The object of research is colza of Maibulak sort.

The soil is ordinary chernozem carbon-bearing argil lo-arenaceous. Mould contents is $5.1 \%$, $\mathrm{pH}$ salty is 6.8 ; nitric nitrogen and flexible phosphorous soil provision was low and with exchange potassium was high.

Tests used the technology accepted for the zone. To increase seeds resistance to adverse effects seeds encrustation was carried out. Encrustant composition was prepared in laboratory conditions, which consisted of glue Na carboxymethyl cellulose and protectant Kruizer 350 (4 liters per ton). Insect fungicide availability in granules prevented colza plantlets from pathogenic flora and plant pests affection. Chemical weed killers were used while tests, the selection of which was on the basis of weed species composition after plantlets appeared. After plantlets appearance processing with chemical weed killers was carried out. Complex action herbicides were used Triumph (0.2 liter per hectare), Pantera $(0.2 \mathrm{l} / \mathrm{h})$ and Samurai $(0.3 \mathrm{l} / \mathrm{h})$. Seeding period in test 1 is according to the accepted scheme, in tests 2 - 3 May, 21 - 25. Seed rate in tests 2 is according to accepted scheme, in tests 1.3 - 2 million germination capacity for 1 ha.

Tests 1 and 2 were completed in crop rotation link: spring crop, colza wheat, blade cultivator was the preceding crop. Test 3 was completed in crop rotation link: pair—spring wheat—spring wheat—colza, spring wheat was used as preceding crop. After preceding crops clearance the soil was processed with blade cultivator checkpoint 2.2 at the depth of $12-14 \mathrm{~cm}$. Snow retention was done twice during the winter with snow ploughs SVS10. Then harrowing in spring with BIG-3 with 2 traces with rolling by roller packers 3KKS-6. During summer soil processing was carried out four times with blade cultivators at the depth of $10-12 \mathrm{~cm}$ twice and $12-14 \mathrm{~cm}$, 14 - 16 to eliminate weeds.

Pre-planting cultivation was completed with direct drills SZS-2.1 with further harrowing by BIG-3 with 2 tracks and rolling by 3KKS-6. Planting was conducted by drills SZS-3.6 at the depth of $2-3 \mathrm{~cm}$ with seeding norm of 1 million of fertile seeds for hectare $(3 \mathrm{~kg} / \mathrm{h})$. Planting was conducted by conditioned seeds, humidity $8 \%$.

Colza harvesting and accounting was completed according to Gossortseti methods (1971) during the phrase of complete seeds maturity. Combined harvester "Sampo-500" was used to harvest in the tests.

Crop producing capacity was recalculated for standard humidity [7].

Statistic experiment data processing was conducted by method of disperse and correlation analysis [8], and economic and bio energetic according to recommendations [9].

\section{Seeding Dates and Norms Influence on Colza Seeds Crops Producing Power}

One of the determining factors while agricultural crops cultivation technology development is the selection of seeding optimal date. This agronomic practice influences significantly crops producing power and its formation [10].

While selecting colza seeding date it is necessary to take into account colza's low competitiveness to weeds and high humidity demand during the phases of budding and juiciness [11].

Colza crops producing power in the conditions of the year 2005 was rather high in the tests (1.3 - 1.6 tons per hectare (t/ha)). The most crops producing power was received from seeding dates of May, $15-20-1.41 \mathrm{t} / \mathrm{ha}$. The variant of May 20th has shown most benefits in drought conditions of Year 2006 (Table 1).

Most crops producing power was received with the variant of seeding date on May 20th $-0.92 \mathrm{t} / \mathrm{ha}$. Also good crops producing power was provided by the variants with seeding date on May 15th and 25th-0.86 and $0.84 \mathrm{t} / \mathrm{ha}$ average. The lowest crops producing power was provided by seeding dates on May, 5th and 10th.

Siberian department of Lenin All-Union Academy of agricultural sciences scholars state that the optimal number of colza plants per 1 square meter is 130 - 150 items [4] [5]. With field emergence within $50 \%$ it is necessary to seed up to 3 million fertile seeds for 1 ha. Seeds harvest did not increase with higher norms of colza seeding in the tests of Siberian oil-bearing crops station. Canadian specialists consider one of colza cultivation peculiarity is its dependence of crops producing capacity of seeding norms. Starikova, V. M., Kuznetsova, V. M. 
Table 1. Seeding dates influence on colza seeds crops producing power (t/ha).

\begin{tabular}{ccccc}
\hline Seeding dates & 2004 & 2005 & 2006 & Average \\
\hline May 5th & 0.43 & 1.22 & 0.39 & 0.68 \\
May 10th & 0.39 & 1.4 & 0.36 & 0.73 \\
May 15th & 0.61 & 1.41 & 0.58 & 0.86 \\
May 20th & 0.74 & 1.41 & 0.61 & 0.92 \\
May 25th (control) & 0.59 & 1.39 & 0.55 & 0.84 \\
May 30th & 0.56 & 1.29 & 0.50 & 0.78 \\
HСР05 & 0.07 & 0.18 & 0.05 & 0.12 \\
\hline
\end{tabular}

etc. (2005) recommend to conduct colza seeding by solid drilling with seeding norm of 2 - 3 million fertile seeds for a hectare (7 - $12 \mathrm{~kg} / \mathrm{ha}$ ) [6] [8] [12]. Optimal conditions of soil and air seeds nutrition are provided with such seeding, even stands appear, in future the plants grow and develop very well.

Satubaldin, K. K. (2004) points out in his works that with seeding norm of 1 million seeds with different middle rows the number of seeds in colza legume was ranging from 17.2 to 18.4 items, with the increase of the norm twice-from 17.6 to 19.9 and with seeding norm 3 million—17.1 - 18.0 seeds, 4 million-17.1 - 17.9 and 5 million-17.0 - 18.1 items [13].

In Zerfus research it is stated that with the increase of colza seeding norm from 3 to 4 million seeds per hectare and crop producing capacity was decreased for 3.2 - 3.5 centner per hectare [14].

Research results have shown that the variant with seeding norm of 1.0 million fertile seeds per hectare provides the most crops producing power. With further increase of seeding norm crops producing power decreases. Less legumes were formed with crowded seeding and they were rather small that led to crops under run. Crop producing power was 0.38 - 0.64 t/ha or $40 \%-67.2 \%$ lower than control in average for 3 years with variants 2 4 million (Figure 1).

Thus, the research has shown that the most stable on the years is colza forming crops producing power with seeding 1.0 million of fertile seeds per hectare. Norm increase contributes to crops overcrowding that negatively influences crops producing power structure, seeds quality and as a consequence crops producing power. Crops producing power with seeding norm 3 - 4 million per hectare was 3 times lower than optimal.

\section{Preceding Crops Influence on Colza Crops Producing Capacity}

One of the most important elements while any agricultural crop cultivation technology development is best preceding crop study and selection.

Many researchers consider that preceding crops influences mineral nutrition elements contents, productive humidity in soil and weed infestation a lot. Present research results coincide with the works carried out by researchers mentioned above. Determination of the crops place in crop rotation plays an important role while maximum use of colza biological potential.

Colza seeds crops producing power that had quite a wide range during test period changed significantly both on the years of research and preceding crops variants. Years of research significantly differed on humidity conditions and temperature regime that is why the primary factor was the amount of precipitation during vegetation period (Table 2).

Thus on all the tests upon average during drought years crops producing power was 0.36 t/ha in 2004, 0.27 t/ha in 2006 and in humid 2005 crops producing power was 4 - 5 times higher and was 1.46 tons.

During the years of research the most stable colza harvests were received with preceding crop subsurface cultivator steam. Preceding crop corn is also the most interesting among other variants. During the years of research on average colza crops producing power in this variant was insignificantly lower but remain rather high -0.68 t/ha which is only 0.13 tons lower than maximum rate received in the control variant with steam subsurface cultivator.

Summer wheat and sty are not at all acceptable as colza preceding crops. Potential weeding is rather high at crops seeding. As a small seeded crop colza produces late shoots which are suppressed at potentially infested fields by weeds that are negatively affected for its seeds productivity. Cost estimate has shown that while fixed costs for colza cultivation cost efficiency was in direct dependence with crops producing power and was $88.1 \%$ with seeding on May 20th. The use of colza seeding high norms of colza is not profitable. In this case high cost 


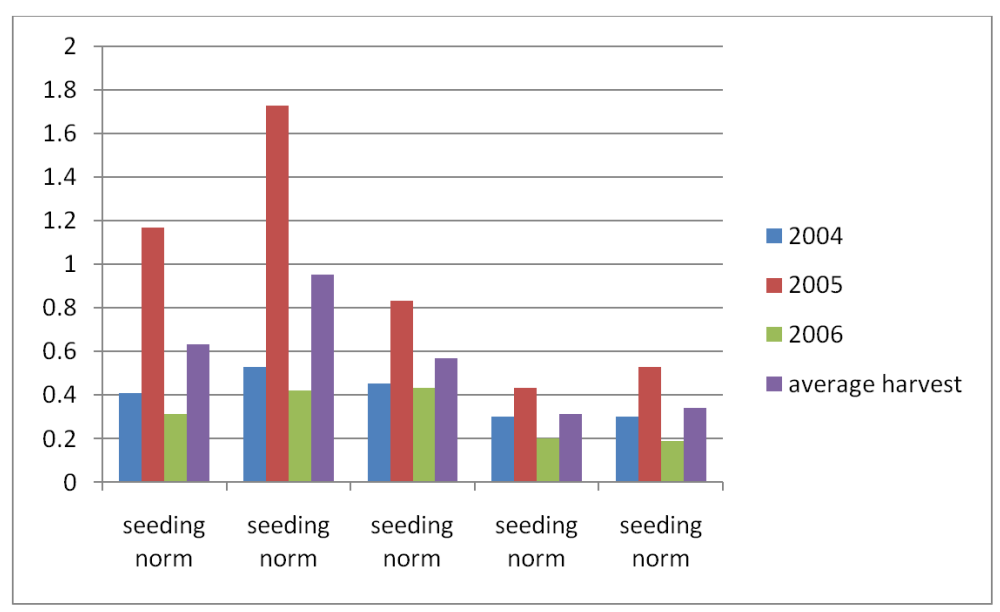

Figure 1. Colza crops producing power depending on seeding norms, t/ha.

Table 2. Colza seeds crops producing power according to preceding crops, t/ha.

\begin{tabular}{ccccc}
\hline \multirow{2}{*}{ Preceding crops } & \multicolumn{3}{c}{ Years of research } & Average \\
\cline { 2 - 4 } Subsurface cultivator steam (control) & 2004 & 2005 & 2006 & 0.81 \\
Dump steam & 0.44 & 1.56 & 0.43 & 0.71 \\
Combined steam & 0.43 & 1.33 & 0.38 & 0.77 \\
Legummed fallow & 0.39 & 1.61 & 0.31 & 0.73 \\
Corn & 0.35 & 1.52 & 0.32 & 0.68 \\
Wheat & 0.31 & 1.46 & 0.29 & 0.56 \\
Sty & 0.29 & 1.33 & 0.08 & 0.59 \\
HCP05 & 0.30 & 1.40 & 0.07 & 0.14 \\
\hline
\end{tabular}

of seeds combined with high costs for equipment exploitation makes colza cultivation unprofitable. The most profitable among preceding crops is sub surface cultivator steam that allows getting net profit of 210 dollar per hectare annually. Colza cultivation is profitable only while using chemical measures complete complex on colza protection. The use of nitrogen and phosphorous fertilizers is the most profitable. Cost efficiency with it is $103 \%$. The use of fertilizers complete complex increases expense reducing cost efficiency correspondingly.

\section{Conclusion}

With the norm of 1 million of fertile seeds per hectare colza crops producing power was 0.95 tons per hectare. Further increase of seeding norm has led to crops producing power decrease for $40 \%-67 \%$. The most colza crops producing power (0.86 and $0.92 \mathrm{t} / \mathrm{ha}$ ) was received while seeding on May 15 th and 20th. Seeding viability decreased significantly during later period due to surface soil layer dehydration, especially with the variant of seeding date on May 30th-48.4\%. Most favorable for colza growth and development preceding crops were sub surface cultivator steam and as for agricultural crops-corn. The lowest crops producing power was received on grain preceding crops. Preceding crops correct selection, seeding dates and norms optimization provides colza seeds high economic efficiency.

\section{References}

[1] Chesnevskiy, A.A. (1996) Basic Elements of Colza Seeds Cultivation Technology in the Steppe Zone of North Kazakhstan. Stavropol, 23 p.

[2] Barayev, A.I. (1966) Scientific Fundamentals of Farming and Ways of Grain Production Increase in Northern Regions of Kazakhstan and Steppe Regions of Western Siberia. In: Problems of Agriculture in North Kazakhstan and Steppe Regions of Western Siberia, Moscow, 28.

[3] Geidebreht, I.P. (1980) Colza Cultivation and Use in Omsk Region. Scientific Technical Bulletin, 1, 31-33. 
[4] Osipova, G.M. (2009) Colza (Biology and Selection Peculiarities in the Conditions of Siberia and Ecological Aspects of the Use). Novosibirk, 132.

[5] Kostin, N.F. (1985) Colza. Kainar, Almaty, 92 p.

[6] Kuznetsova, R.Y. (1975) Colza Is a High Productivity Crop. Kolos, Leningrad, 83 p.

[7] Dospehov, B.A. (1979) Methods of Field Experiment: With the Basis of Statistic Research Results Processing. Moscow, 416.

[8] Korenevskiy, V.I. (1985) To the Methods of Statistic Processing of Many Years Experiments. Agriculture, 11, 56.

[9] Yermohin, Y.I. (1994) Economic and Bio Energetic Evaluation of Fertilizers Use. Omsk, 44.

[10] Malahov, G.N. (1983) Colza Seeding Dates. Uralskiyenivy, 5, 26-27.

[11] Milashchenko, N.Z. (1989) Colza and Coleseed Cultivation and Use Technology. 223 p.

[12] Starikova, V.M. (2005) Recommendations on Colza and Coleseed Cultivation in Omsk Region. Isilkul, 11 p.

[13] Satubaldin, K.K. (2004) Technology Basic Elements Substantiation of Colza and Coleseed Cultivation at Middle Ural. Yekaterinburg, 265 p.

[14] Zerfus, V.M. (1993) Zoning and Colza and Coleseed Cultivation Technology Substantiation in Western Siberia. Omsk, $34 \mathrm{p}$. 
Scientific Research Publishing (SCIRP) is one of the largest Open Access journal publishers. It is currently publishing more than 200 open access, online, peer-reviewed journals covering a wide range of academic disciplines. SCIRP serves the worldwide academic communities and contributes to the progress and application of science with its publication.

Other selected journals from SCIRP are listed as below. Submit your manuscript to us via either submit@scirp.org or Online Submission Portal.
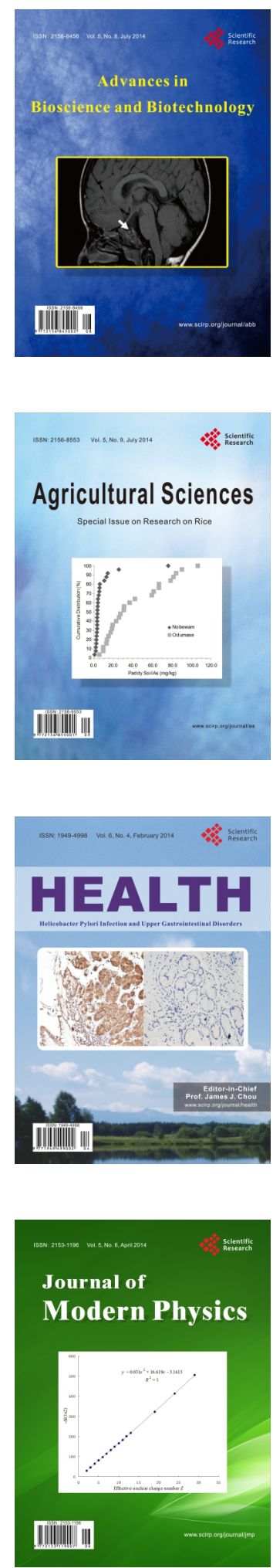
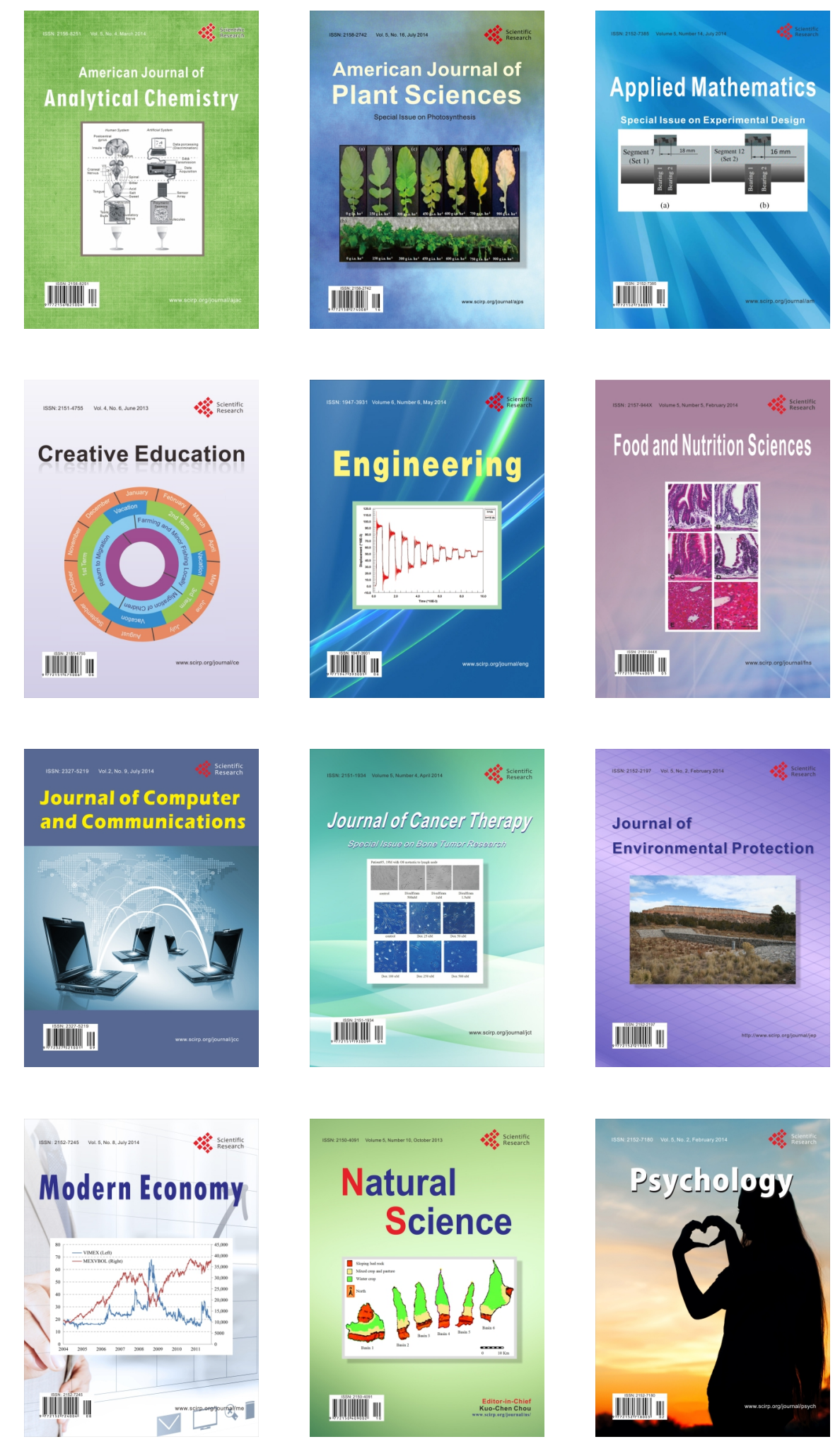